\title{
Kinetics of Chemical Vapour Deposition of Boron Nitride from a Gas Mixture of Trimethylborazine, Ammonia, and Hydrogen at 900 to $1050{ }^{\circ} \mathrm{C}$ and 1 Bar Total Pressure
}

\author{
A. Jörg, D. Neuschütz and E. Zimmermann
}

Lehrstuhl für Theoretische Hüttenkunde, RWTH Aachen, 52056 Aachen, Germany

\begin{abstract}
The kinetics of CVD of boron nitride from a gas mixture of 1,3,5-tri(N-methyl)borazine (TMB), ammonia, and hydrogen were studied at 900 to $1050^{\circ} \mathrm{C}$ and a total pressure of 1 bar.

$\mathrm{TMB}$, a liquid between -3 and $136^{\circ} \mathrm{C}$, is assumed to be a single source precursor for CVD of BN. However, to suppress gas phase nucleation, one has to add sufficiently large amounts of ammonia. Below $900^{\circ} \mathrm{C}$ no deposition was observed with in 10 hours. Between 900 and $980^{\circ} \mathrm{C}$ the deposition rate was controlled by a surface reaction with an apparent activation energy of $145 \mathrm{~kJ} \mathrm{~mol}^{-1}$. The reaction was found to be first-order with respect to TMB and zero-order in both $\mathrm{NH}_{3}$ and $\mathrm{H}_{2}$. Above $1000^{\circ} \mathrm{C}$ the activation energy decreased to $26 \mathrm{kJmol}^{-1}$ which corresponds to gas diffusion as the rate-determining step. Gas phase nucleation makes it difficult to produce smooth films above $1000^{\circ} \mathrm{C}$.
\end{abstract}

The reaction product was turbostratic hexagonal boron nitride with about 52 at.- $\%$ nitrogen, 46 at. - \% boron, and 1-2 at.- \% codeposited carbon.

\section{INTRODUCTION}

Fiber-reinforced ceramic matrix composites (CMCs) are known to combine high oxidation resistance at elevated temperatures with high work of fracture and crack propagation resistance. Such properties of CMCs are possible only by proper control of the fiber-matrix interface [1-6|. In contrast to composites with polymeric or metallic matrices the fiber-matrix binding has to be weak in CMCs. This results in a substantial pullout and a quasiductile behaviour under tensile stress. An interlayer of graphitic carbon or hexagonal boron nitride between fiber and matrix leads to the desired weak binding. $\mathrm{BN}$ is more resistant to oxidation than carbon.

Hexagonal BN interlayers are generally produced by chemical vapour infiltration (CVI). Common precursors are chloroborazines [7,8,9] or mixtures of $\mathrm{BCl}_{3}$ and $\mathrm{NH}_{3}[10]$ or of $\mathrm{BF}_{3}$ and $\mathrm{NH}_{3}$ $[11,12,13]$. Because of the high toxicity of these boron compounds it is desirable to find a new. nontoxic precursor. This precursor should have a thermal stability rendering possible CVI with high deposition rates. In order to get smooth films of uniform thickness even on substrates of complex geometries, the deposition process should be controlled by chemical reaction and not by gas diffusion. A total pressure of 1 bar is preferable in view of the economics of the technical process.

According to Adams [14] borazine is not stable enough to deposit BN films with high deposition rates by thermal decomposition. Substitution of three hydrogen atoms by methyl groups increases the thermal stability of borazine, so that it can be used in the CVI process. This 1,3,5-tri(N-methyl)borazine (TMB), a liquid between $-3^{\circ} \mathrm{C}$ and $136^{\circ} \mathrm{C}$, was first investigated by Weber et al. [15] with respect to its potential for CVD. 


\section{EXPERIMENTAL}

Using TMB (Solvay) and ammonia as precursors, and hydrogen as carrier gas, films have been deposited in a vertical hot wall reactor. The reactor is a mullite tube of $34 / 28 \mathrm{~mm}$ diameter with a parabolic cemperature profile along the tube axis and a quasi-isothermal zone of about $5 \mathrm{~cm}( \pm 5 \mathrm{~K})$.

Purities of ammonia and hydrogen were $>99.999 \%$, of methane $>99.5 \%$. For the gases electronic mass flow controllers were used. TMB concentration was varied using a system combining an evaporator and a reflux-condenser purged by $10 \mathrm{NIh}^{-1}$ hydrogen. All experiments were carried out at 1 bar total pressure.

Substrate materials were graphite for the kinetic experiments, alumina for XRD analysis, and graphite or silicon for electron probe microanalysis (EPMA).

The deposition rate was measured continuously by means of a magnetic levitation thermobalance (Sartorius) described previously $|16,17,18|$.

The compositions of the coatings were obtained by EPMA and X-ray photoelectron spectroscopy (XPS). The crystal structure of the films was examined by X-ray diffraction (XRD) using nickel-filtered CuK ${ }_{r}$ radiation.

\section{RESULTS AND DISCUSSION}

\subsection{Thermodynamics}

In order to find suitable process parameters for the deposition of pure boron nitride thermodynamic equilibrium calculations were performed making use of the ChemSage program [19], Fig.1.

From pure $\mathrm{TMB}(\log (\mathrm{C} / \mathrm{B})=0, \log (\mathrm{N} / \mathrm{B})=0, \log (\mathrm{H} / \mathrm{B})=0.6)$, codeposition of the three solid phases $\mathrm{C}, \mathrm{B}_{4} \mathrm{C}$, and $\mathrm{BN}$ is predicted. Fig. 1 shows that codeposition of carbon decreases by decreasing both temperature and TMB concentration. By raising the activity of nitrogen it is possible to extend the stability range of pure $B N$.

On the basis of the equilibrium calculations, most suitable conditions for the deposition of single phase $\mathrm{BN}$ are, at $1200 \mathrm{~K}$, ratios of $\mathrm{N} / \mathrm{B} \geq 3, \mathrm{H} / \mathrm{B} \geq 150$, and $\mathrm{C} / \mathrm{B}=1$.

\subsection{Kinetics}

The deposition of smooth films was possible only by adding to the carrier gases ( $\mathrm{Ar}, \mathrm{H}_{2}, \mathrm{~N}_{2}$ ) a certain amount of ammonia. Ammonia also helped to avoid gas phase nucleation. Therefore, the gas composition chosen for all further experiments was 0.035 to $0.16 \% \mathrm{TMB}, 75 \% \mathrm{H}_{2}$ and $25 \% \mathrm{NH}_{3}$.

The deposition rate increased with inreasing total gas flow rate and became independent of the flow rate at $100 \mathrm{~N}^{-1} \mathrm{~h}^{-1}\left(900^{\circ} \mathrm{C}\right)$ and $150 \mathrm{Nh}^{-1}\left(1000^{\circ} \mathrm{C}\right)$, Fig.2. Above these critical gas velocities, the deposition rate was solely determined by the chemical surface reaction.

The influence of temperature on the deposition rate determined at constant gas composition and gas flow (100 $\mathrm{NIh}^{-1}$ ) is shown in Fig. 3: In the range from 900 to $980^{\circ} \mathrm{C}$, the Arrhenius plot yields a straight line with an activation energy of $E_{1}=145 \mathrm{kJmol}^{-1}$, while above $1000^{\circ} \mathrm{C}$, the rate shows a much weaker temperature dependence with $E_{\mathrm{Il}}=26 \mathrm{~kJ} \mathrm{~mol}^{-1}$. At the higher temperatures, the deposition rate was apparently determined by gas diffusion. Below $1000^{\circ} \mathrm{C}$ the measured rates seem to represent the heterogeneous deposition reaction. Similar activation energies have been reported for $\mathrm{BN}$ deposition from the $\left.\mathrm{BCl}_{3}-\mathrm{NH}_{3}-\mathrm{I} 10,20,2 \mathrm{l}, 22\right]$ and the $\mathrm{BF}_{3}-\mathrm{NH}_{3}$-systems [13]. Variations of the mole fraction of TMB $\left(\mathrm{x}_{\mathrm{TMB}}\right)$ in the temperature range 900 to $1050^{\circ} \mathrm{C}$ led to a reactiols order of 1 with respect to TMB. Fig. 4. The reaction orders with respect to ammonia and hydrogen were found to be zero (Fig.5 and 6). The fact that the deposition rate proved independent of the ammonia concentration may lead to the con- 


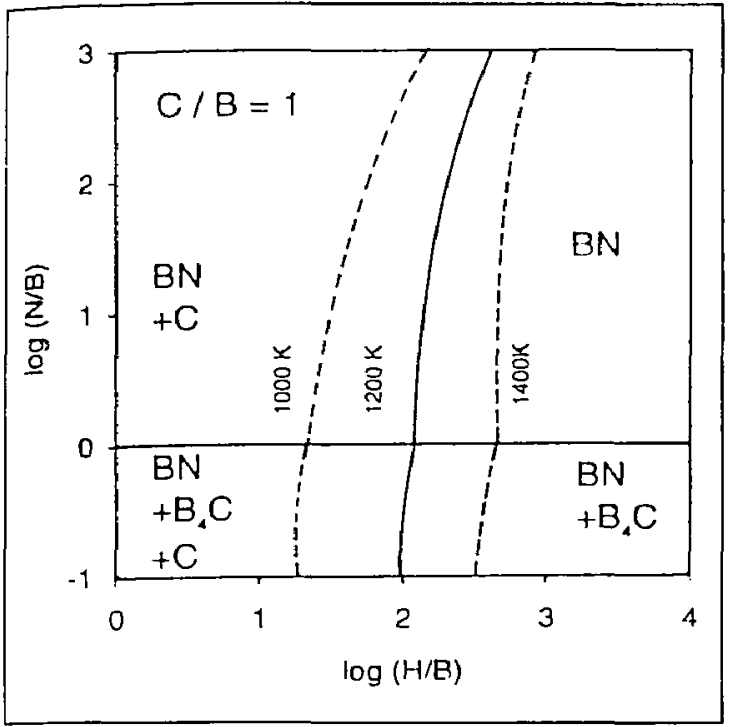

Fig.1: Calculated phase equilibria in the system B-N-C-H

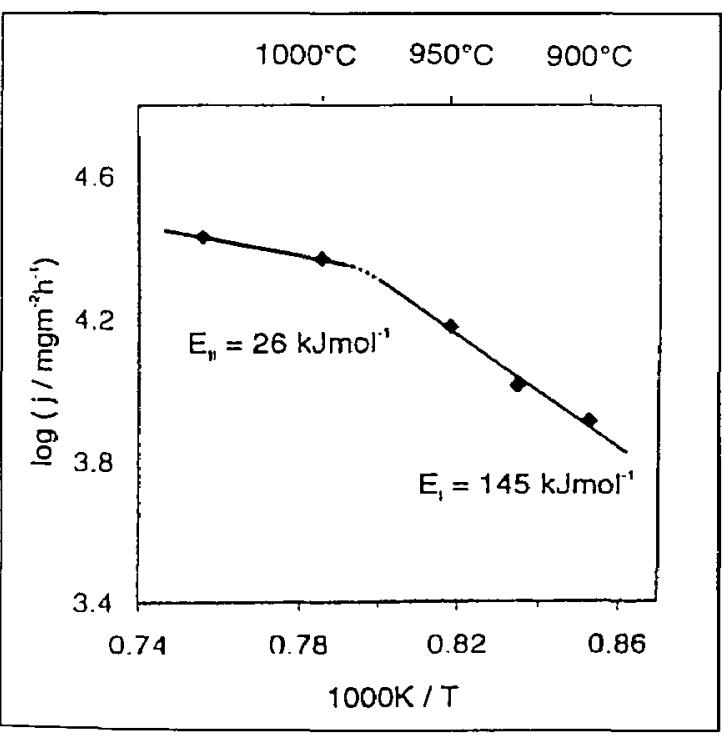

Fig. 3: Temperature dependence of deposition rate at constant gas velocity $\left(100 \mathrm{Nlh}^{-1}\right)$ and feedgas composition; mole fractions: $\mathrm{TMB}=1.0^{*} 10^{-3}, \mathrm{H}_{2}=0.75$. $\mathrm{NH}_{3}=0.25$,

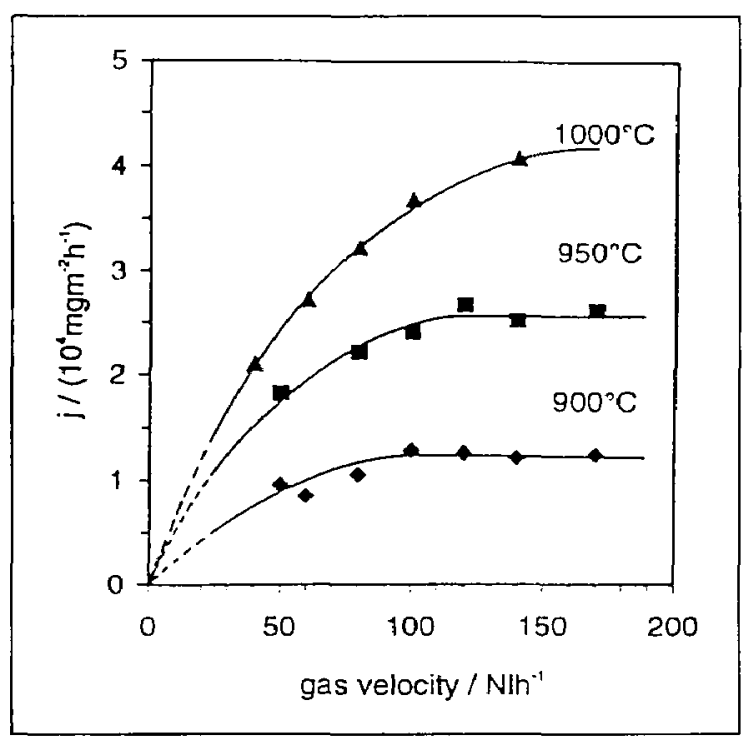

Fig.2: Deposition rate vs. gas velocity at constant feedgas composition; mole fractions: $T M B=1.58 * 10^{-3}, H_{2}=0.75$, $\mathrm{NH}_{3}=0.25$

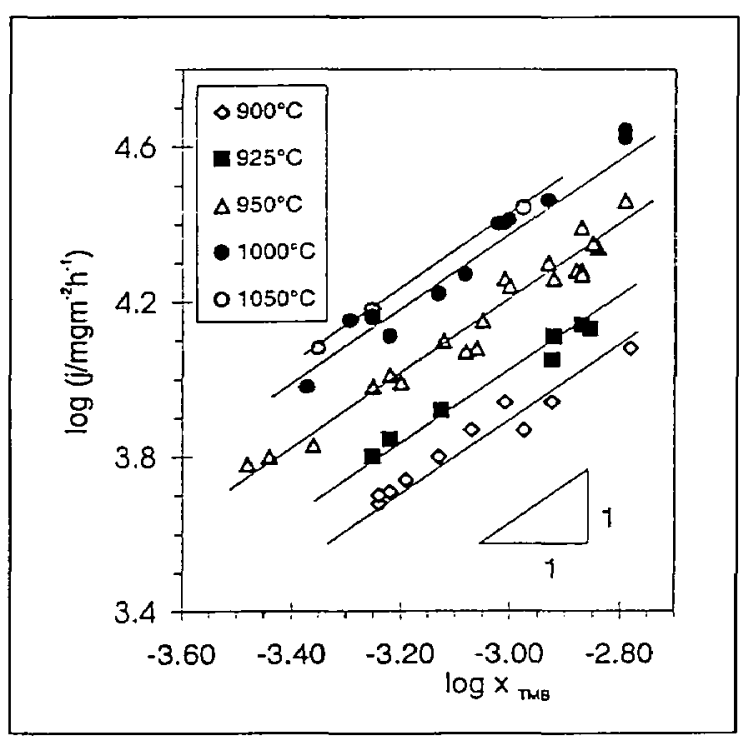

Fig. 4: Deposition rate vs. TMB concentration $\mathrm{x}_{\mathrm{TMB}}$ in feedgas at constant gas velocity $\left(100 \mathrm{Nlh}^{-1}\right)$; mole fractions: $\mathrm{H}_{2}=0.75$. $\mathrm{NH}_{3}=0.25$ 
clusion that preceding reactions in the gas phase do not noticeably influence the deposition rate of BN. The rate of chemical vapour deposition of boron nitride from TMB, $\mathrm{H}_{2}$, and $\mathrm{NH}_{3}$ may thus be summarized as follows:

$\mathrm{j}_{\mathrm{BN}}=6.39 \cdot 10^{6} \cdot \mathrm{x}_{\mathrm{TMB}}^{1} \cdot \exp \left(\frac{145000}{\mathrm{RT}}\right) \quad\left[\mathrm{g} \mathrm{m}^{-2} \mathrm{~s}^{-1}\right]$

This equation is valid at 900 to $980^{\circ} \mathrm{C}$ for mole fractions of hydrogen from 0.1 to 0.95 , of ammonia from 0.05 to 0.49 , and of TMB from $3.5^{*} 10^{-4}$ to $1.6^{*} 10^{-3}$ and at gas flow rates above $100 \mathrm{Nlh}^{-1}$ in a tube reactor of $28 \mathrm{~mm}$ inner diameter.

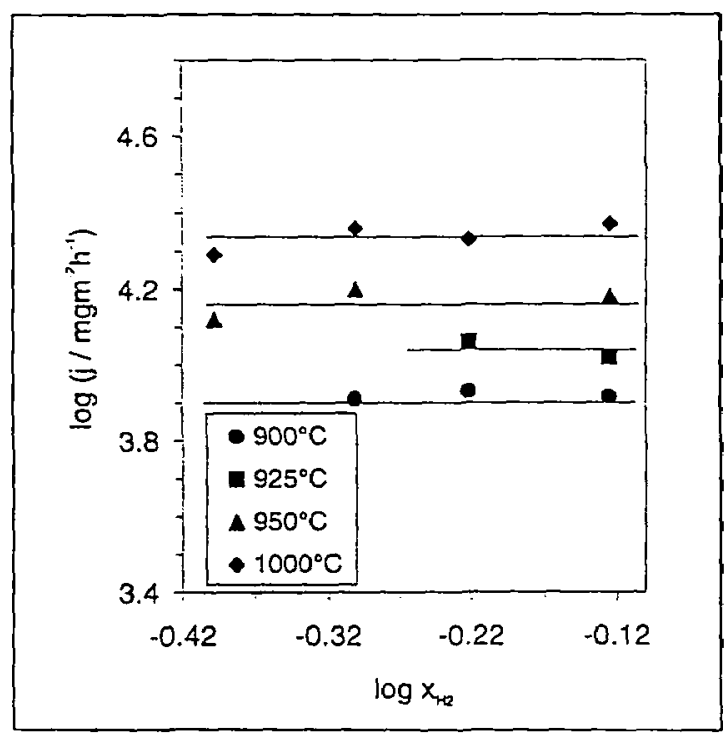

Fig. 5: Deposition rate vs. $\mathrm{H}_{2}$ concentration in feedgas; gas velocity: $100 \mathrm{NIh}^{-1}$; mole fractions: $\mathrm{NH}_{3}=0.25, \mathrm{TMB}=1.0^{*} 10^{-3}$, balance Ar

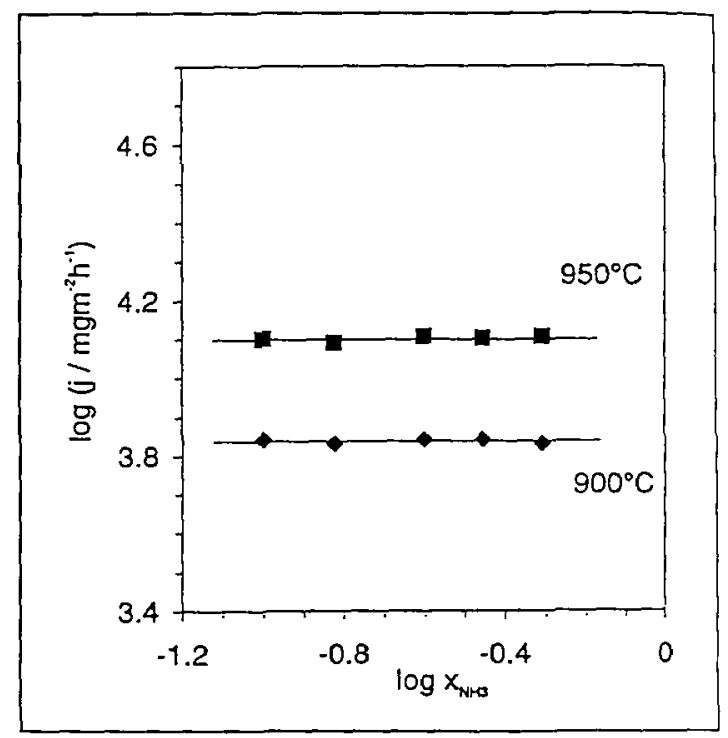

Fig. 6: Deposition rate vs. $\mathrm{NH}_{3}$ concentration in feedgas; gas velocity: $100 \mathrm{Nlh}^{-1}$; mole fractions: $\mathrm{TMB}=0.83 * 10^{-3}$. balance $\mathrm{H}_{2}$

\subsection{Characterization of the films}

The films deposited on alumina were characterized by XRD. Fig.7 shows a typical X-ray diffraction pattern of a layer formed at $900^{\circ} \mathrm{C}$ on an $\mathrm{Al}_{2} \mathrm{O}_{3}$ substrate. The most distinct peaks are the alumina reflexes. The broader peaks are related to the (002)-, (10)-, (004)-, and (110)-peaks of hexagonal BN with a lack of higher induced peaks characteristic for turbostratic BN ( $t-B N$ ), a hexagonal structure lacking three-dimensional ordering ${ }^{1}$. In $\mathrm{t}-\mathrm{BN}$ the individual $\mathrm{BN}$-layers are arranged roughly parallel to one another but at random in translation parallel to the layer, and rotated about the normal $|20,23|$.

1 (10) is a common abbreviation for the superposed (100)- and (101)-peaks in turbostratic materials. 


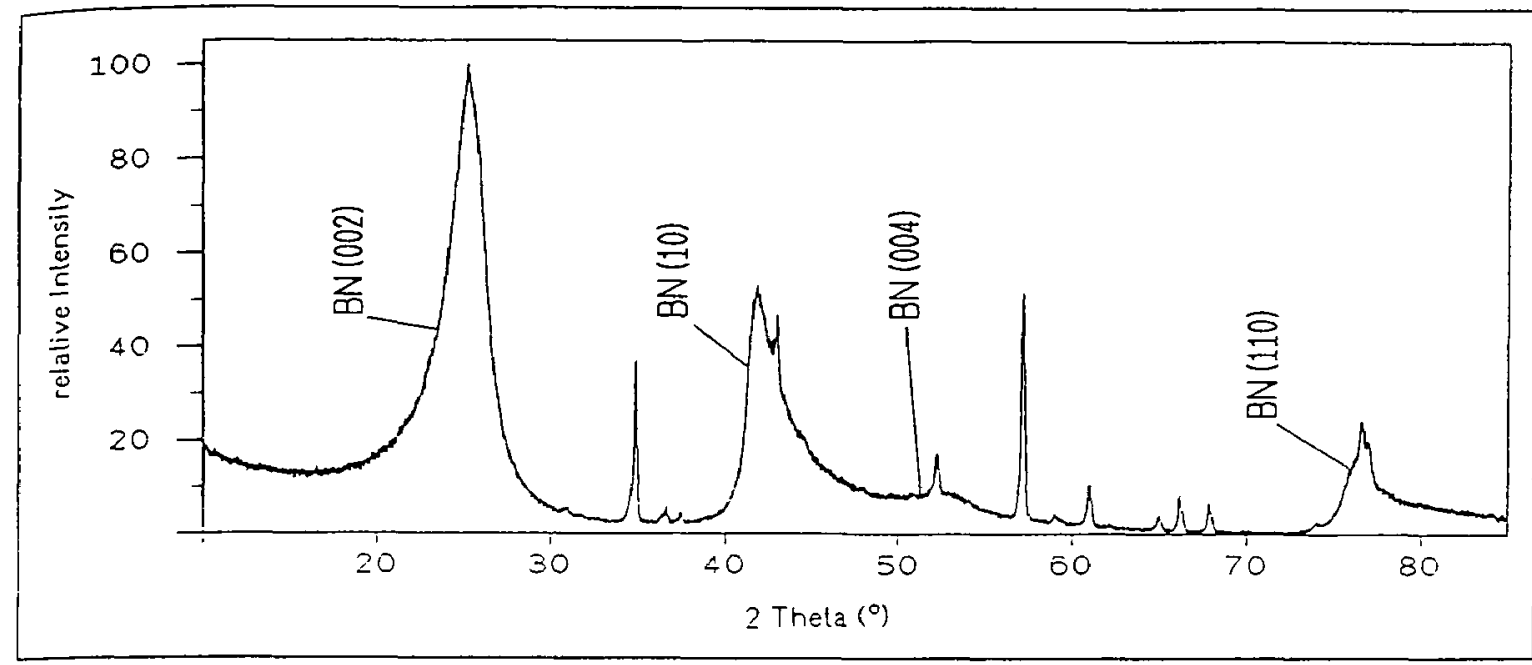

Fig.7: XRD-pattern of $\mathrm{BN}$ on alumina substrate; $\mathrm{CuK}_{\alpha}$-radiation; angle of incidence: $3^{\circ}$; deposition temperature $900^{\circ} \mathrm{C}$, gas velocity: $100 \mathrm{NIh}^{-1}$, mole fractions $\mathrm{H}_{2}=0.75, \quad \mathrm{NH}_{3}=0.25$. $\mathrm{TMB}=0.87^{*} 10^{-3}$; the most distinct peaks are related to alumina, the broader peaks to turbostratic boron nitride

For EPMA investigations films were coated with several nanometers of gold to avoid charging. The results obtained with EPMA, Tab.1, suggest that the coatings were boron nitride with a N/B-ratio $>1$, the average ratio being 1.18 . The nitrogen surplus in the film seemed to become higher with increasing TMB content in the feedgas. The carbon contents in the films were found to be between 2 and 4 at. $\%$ and did neither vary noticeably with TMB concentration nor with temperature.

The EPMA analyses of samples no. 1 to 5 showed a relatively large scatter of \pm 6 at. $-\%$ in $B$ and $N$, Tab.1. This error is related to the high roughness of these samples deposited in a thickness of about $50 \mu \mathrm{m}$ on graphite substrates. To decrease the scatter, another two samples were prepared on extremely flat substrates, Si wafers, and with very low thickness $(350-500 \mathrm{~nm})$. Moreover, charging of these samples during EPMA was avoided because these thicknesses were less than the penetration depth of primary electrons $(\approx 500 \mathrm{~nm})$. The EPMA analyses of these samples are summarized in Tab.2. Both thin coatings were deposited at $900^{\circ} \mathrm{C}$ and a TMB concentration of $0.087 \%$, but with different gas phases: Sample 6 with a gas phase of $75 \% \mathrm{H}_{2}, 25 \% \mathrm{NH}_{3}$ (similar to samples 3 and 4), and sample 7 with a gas phase of $70 \% \mathrm{H}_{2}, 10 \% \mathrm{NH}_{3}$, and $20 \% \mathrm{CH}_{4}$. Both samples show again the relatively large nitrogen surplus observed before. While the analytic scatter decreased with smoother sample surfaces, the average N/B-ratio, here 1.14 , remained practically unchanged. The carbon content was $\leq 1$ at. $\%$ in these samples, lower than before. Increased carbon activity in the feedgas (by addition of methane during deposition of sample 7) did not lead to a noticeable rise in carbon deposition.

Several samples were also analyzed by XPS, Tab.3. XPS analysis showed a boron surplus which even increased during sputtering. The carbon content determined by XPS decreased from 10-15 at. $\%$ without sputtering to $6-8$ at.- \% after $30 \mathrm{~min}$ sputtering. Further sputtering did not remove additional carbon from the surface. The $\mathrm{C}$ is peak of sample $8, \underline{\text { Fig. } 8}$, shows graphitic carbon binding only. The oxygen content was less than the detection limit of 1 at.-\%.

The XPS analyses are partially in contradiction to EPMA. One reason is that XPS analyzes only the first molecular layers making it extremely sensitive to surface contaminations, adsorption phenomena. or differences in sputtering yield. The higher sputtering yield of nitrogen as compared to boron has been 
reported $[12,24]$. Contamination of the surface by hydrocarbons when the films were exposed to air is an explanation for the apparent higher carbon content of XPS analysis. Such adsorbed hydrocarbons are resistant to sputtering |24|. The binding state of carbon of the films was not clear as most of the C. Is spectrum originated from adsorbed hydrocarbons. The oxygen contents of the films depended on the time which the films were exposed to air. This behaviour is explained by the absorption of water, since turbostratic boron nitride is known to react rapidly with moisture $[14,23,25]$. It may therefore be concluded that the original deposit was free of oxygen. XPS analysis showed that samples had less than. 1 at. $\%$ oxygen from the C.VD process if they were carefully handled.

In comparing EPMA and XPS results, the EPMA analyses are taken to be more representative for the bulk deposits. The average N/B-ratio of the boron nitride deposited was then around $1.15 \pm 0.1$, all samples displaying a certain nitrogen surplus. Overstoichiometric nitrogen in BN is known from Elena et al. [26]. Regularly the layers contained 1-2 at.- $\%$ codeposited carbon. The oxygen content was found to be caused by later contact of the sample with the atmosphere.

The surface morphology was smooth when the deposition took place in the surface reaction controlled range (Fig.9). This is important for the infiltration of CMCs.

Tab. 1: Electron probe microanalysis of films deposited at different temperatures and TMB concentrations; samples are coated with 10-20 nm Au; film thickness $>50 \mu \mathrm{m}$; substrate material: graphite; mole fractions: $\mathrm{H}_{2}=0.75, \mathrm{NH}_{3}=0.25$, for sample $5: \mathrm{H}_{2}=0.4, \mathrm{NH}_{3}=0.25, \mathrm{Ar}=0.35$

\begin{tabular}{|ccccccc|}
\hline sample no. & $\vartheta /{ }^{\circ} \mathrm{C}$ & $\mathrm{x}_{\mathrm{TMB}} / 10^{-4}$ & $\mathrm{~B} /$ at. $\%$ & $\mathrm{~N} /$ at. $\%$ & $\mathrm{C} /$ at. $\%$ & $\mathrm{O} /$ at. $\%$ \\
1 & 950 & 15 & $42.2 \pm 2.8$ & $49.8 \pm 4.4$ & $4.1 \pm 1.5$ & $3.9 \pm 0.5$ \\
2 & 950 & 4 & $46.0 \pm 5.9$ & $48.6 \pm 7.0$ & $2.6 \pm 0.2$ & $2.8 \pm 0.7$ \\
3 & 900 & 12 & $40.8 \pm 5.8$ & $52.9 \pm 7.9$ & $2.2 \pm 0.3$ & $4.1 \pm 0.5$ \\
4 & 900 & 6 & $46.9 \pm 5.3$ & $48.6 \pm 8.2$ & $2.3 \pm 0.7$ & $2.2 \pm 0.7$ \\
5 & 900 & 10 & $40.1 \pm 6.0$ & $53.3 \pm 9.0$ & $2.0 \pm 0.2$ & $4.7 \pm 0.1$ \\
\hline
\end{tabular}

Tab.2: EPMA of films deposited at $900^{\circ} \mathrm{C}$ from different gas phases at a mole fraction of TMB of $0.87 * 10^{-3}$; substrate material: $\mathrm{Si}$-wafer

\begin{tabular}{|ccccccc|}
\hline $\begin{array}{c}\text { sample } \\
\text { no. }\end{array}$ & $\begin{array}{c}\text { coating- } \\
\text { thickness }\end{array}$ & gas phase & $\mathrm{B} /$ at. $\%$ & $\mathrm{~N} /$ at. $\%$ & $\mathrm{C} /$ at. $\%$ & $\mathrm{O} /$ at. $\%$ \\
6 & $486 \mathrm{~nm}$ & $\begin{array}{r}25 \% \mathrm{NH}_{3}, \\
75 \% \mathrm{H}_{2}\end{array}$ & $46.1 \pm 1.6$ & $52.0 \pm 1.6$ & $0.8 \pm 0.04$ & $1.1 \pm 0.03$ \\
& & & & & \\
7 & $372 \mathrm{~nm}$ & $\begin{array}{c}70 \% \mathrm{NH}_{3}, \\
10 \% \mathrm{NH}_{4},\end{array}$ & $44.8 \pm 1.4$ & $51.4 \pm 1.6$ & $1.0 \pm 0.04$ & $2.8 \pm 0.05$ \\
\hline
\end{tabular}


Tab.3: XPS analysis of coatings deposited from different gas phases at a mole fraction of TMB of $0.87 * 10^{-3}$; film thickness $>10 \mu \mathrm{m}$; substrate material: graphite

\begin{tabular}{|ccccccc|}
\hline $\begin{array}{c}\text { sample } \\
\text { no. }\end{array}$ & $\begin{array}{c}\text { sputter } \\
\text { time }\end{array}$ & gas phase & $\mathrm{B} /$ at. $\%$ & $\mathrm{~N} /$ at. $\%$ & $\mathrm{C} /$ at. $\%$ & $\mathrm{O} /$ at. $-\%$ \\
8 & $0 \mathrm{~min}$ & $25 \% \mathrm{NH}_{3}$, & 48.6 & 41.8 & 9.6 & $<1.0$ \\
& $30 \mathrm{~min}$ & $75 \% \mathrm{H}_{2}$ & 54.1 & 39.2 & 6.7 & $<1.0$ \\
& & & & & $<1.0$ \\
9 & $0 \mathrm{~min}$ & $74.7 \% \mathrm{H}_{2}$, & 48.0 & 39.2 & 15.8 & $<1.0$ \\
& $30 \mathrm{~min}$ & $25 \% \mathrm{NH}_{3}$, & 53.2 & 38.5 & 8.3 & \\
\hline
\end{tabular}

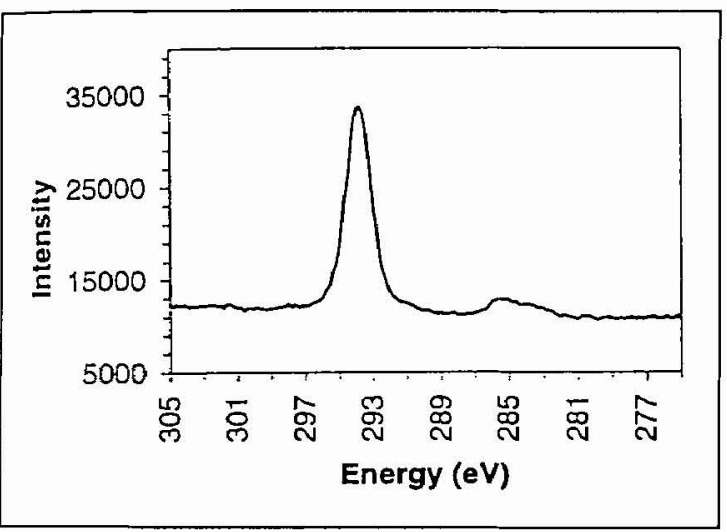

Fig. 8: C 1s spectrum of 30 min sputtered BN film (sample 8)

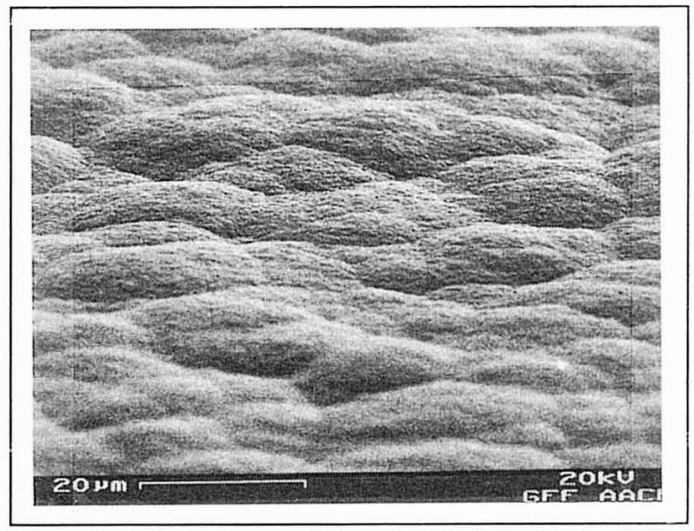

Fig.9: Scanning electron micrograph (sample 4)

\section{CONCLUSION}

TMB has proven to be a suitable precursor for the infiltration of CMCs with $\mathrm{BN}$ between $900^{\circ} \mathrm{C}$ and $980^{\circ} \mathrm{C}$ and a total pressure of 1 bar. Under these conditions and at sufficient gas velocity in a vertical tube reactor, the deposition rate is determined by the surface chemical reaction. The reaction orders are one with respect to TMB and zero with respect to $\mathrm{H}_{2}$ and $\mathrm{NH}_{3}$.

The overall reaction is: $\quad \mathrm{H}_{3} \mathrm{~B}_{3} \mathrm{~N}_{3}\left(\mathrm{CH}_{3}\right)_{3} \rightarrow 3 \mathrm{BN}+3 \mathrm{CH}_{4}$

and the rate equation is given by

$\mathrm{j}_{\mathrm{BN}}=6.39 \cdot 10^{6} \cdot \mathrm{x}_{\mathrm{TMB}}^{1} \cdot \exp \left(-\frac{145000}{\mathrm{RT}}\right) \quad\left[\mathrm{g} \mathrm{m}^{-2} \mathrm{~s}^{-1}\right]$

To avoid gas phase nucleation one has to add several percent of ammonia to the feedgas. The reaction product is a turbostratic boron niride with about 52 at.-\% nitrogen, 46 at.-\% boron, and 1-2 at.-\% codeposited carbon. 


\section{REFERENCES}

[1] S. Prouhet, G. Camus, C. Labrugère, A. Guette: J. Am. Ceram. Soc. 77 (1994) 649-656

[2] E. Y. Sun, S. R. Nutt, J. J. Brennan: Proc. 18th Ann. Cont. Comp. \& Adv. Ceram. Mater.B 1993, Cocoa Beach, FL (K.V. Logan) in Ceram. Eng. \& Sci. Proc., 1994, 943

[3] B. Bender, D. Shadwell, C. Bulik, L. Incorvati, D. Lewis III.: Am.Ceram. Soc.Bull.65 (1986) 36]

[4] R. N. Singh, M. K. Brun: Adv. Ceram. Mat. 3 (1988) 235-237

[5] R. D. Veltri, F. S. Galasso: J. Am. Ceram. Soc. 73 (1990) 2137-2140

[6] R. Naslain, O. Dugne, A. Guette, J. Sevely, C. R. Brosse, J.-P. Rocher, J. Cotteret: J. Am. Ceram. Soc. 74 (1991) 2482-2488

[7] R. N. Singh: Proc. 10th Int. Conf. on CVD 1987 (ed. by G. W. Cullen), The Electrochem. Soc. Princeton, NJ, 543-551

[8] J. J. Gebhardt: Proc. 4th Int. Conf. on CVD 1973 (ed. by G. F. Wakefield, J. M. Blocher, Jr.) The Electrochem. Soc., Princeton, NJ, 460-472

[9] G. Constant, R. Feurer: J. Less-Common Met. 82 (1981) 113-118

[10] N. Patibandla, K. L. Luthra: J. Electrochem. Soc. 139 (1992) 3558-3565

[11] H. Hannache, R. Naslain, C. Bernard: J. Less Common Met. 95 (1983) 22 1-246

[12] C. Guimon, D. Gonbeau, G. Pfister-Guillouzo, O. Dugne, A. Guette, R. Naslain, M. Lahaye, Surf. \& Interface Analysis 19 (1990) 440-445

[13] S. Prouhet, A. Guette, F. Langlais: Proc. 8th Europ. Conf. on CVD 1991, Glasgow, Scotland. (Ed. by L. Hitchman, N.J. Archer), C2.119-126

[14] A. C. Adams: J. Electrochem. Soc. 128 (1981) 1378-1379

[15] A. Weber, U. Bringmann, C.-P. Klages, R. Nikulski, Dünnschichttechnologien '92 (VDI-Verlag. Düsseldorf 1993), 110-119

[16] D. Neuschütz, F. Salehomoum: Mat. Res. Soc. Symp. Proc. Vol. 250 (1991), CVD of Refractory Met. \& Ceram.II (ed. by T. M. Besmann, B. M. Gallois, J. W. Warren), 4l-46

[17] C.Delhaes, D. Neuschütz: will be published in Proc. MRS Fall Meeting, Boston MA (USA), Nov 1994, Mat. Res. Soc. Symp. Proc. Vol. 363 (1995)

[18] D. Neuschütz, S. Zimdahl, E. Zimmermann: Proc. 12th Int. Symp. on CVD 1993 (ed. by K. F. Jensen, G. W. Cullen), The Electrochem. Soc., Princeton, NJ, 1-7

[19] G. Eriksson, K. Hack: Met. Trans.B 21B (1990) 1013-1023

[20] T. Matsuda, H. Nakae, T, Hirai: J. Mat. Sci. 23 (1988) 509-514

[21] W.Y Lee, W.J. Lackey, P.K. Agrawal: J. Am. Ceram. Soc. 74 (1991) 2642-2648

[22] H. Tanji, K. Monden, M. Ide: Proc. 10th Int. Conf. on CVD 1987 (ed. by G. W. Cullen, The Electrochem. Soc., Princeton, NJ, 562-569

[23] T. Matsuda: J. Mat. Sci. 24 (1989) 2353-2358

[24] D. Briggs, M. P. Seahl, Practical Surface Analysis by Auger and X-ray Photoelectron Spectroscopy, John Wiley \& Sons Ltd. 1983

[25] F. Saugnac, F. Teyssandier, A. Marchand: J. Am. Ceram. Soc. 75 (1992) 161-169

[26] M. Elena, L. Guzman, L. Calliari, L. Moro, A. Steiner, A. Miotello, M. Bonelli, R. Capelletti, P. M. Ossi: Thin Solid Films 253 (1994) 78-84 